\title{
DEVELOPING ACADEMIC SKILLS IN DIGITAL ENVIRONMENTS: MEDIA EFFECTS ON PERFORMANCE AND METACOGNITIVE JUDGMENTS
}

\author{
Gal Ben-Yehudah ${ }^{1}$, \& Ronen Kasperski ${ }^{2,3}$ \\ ${ }^{1}$ Department of Education and Psychology, The Open University (Israel) \\ ${ }^{2}$ Department of Special Education, Gordon Teachers College (Israel) \\ ${ }^{3}$ Department of Special Education, Shaanan Teachers College (Israel)
}

\begin{abstract}
The prevalence of digital academic materials and their use is constantly growing. However, surveys report that most readers prefer to read long texts such as academic papers and textbooks in print rather than digital format. Moreover, accumulating evidence on in-depth processing of digital text points to the disturbing finding - understanding digital text is inferior to that of printed text. In an effort to overcome these contradictory trends, the current study investigated the effectiveness of an instructional intervention for preservice teachers, which focused on developing academic reading and writing skills in a digital environment. The instruction took place in a computer lab, during which the instructor demonstrated reading and writing strategies in a digital environment using frontal teaching methods. Then, the participants practiced these strategies in their scientific reading and writing. Multiple testing points were implemented in both media conditions: digital and paper. The mid-term testing point demonstrated that emphasizing in-depth processing diminished the 'media effect' (differences in performance between digital and paper conditions) reported in the literature for reading comprehension. Also there were no differences in academic writing between paper and digital groups. Confidence ratings for academic reading and writing were higher in the digital setting. Interestingly, differences in the evaluation (calibration analyses) of reading and writing were observed among media groups. While the digital group was more calibrated on their assessment of writing quality, the paper group was more calibrated in their assessment of reading comprehension. In this paper, we will discuss the importance of incorporating a digital module into the curriculum of preservice teachers, which should increase students' awareness to biases they may have about academic performance in digital environments.
\end{abstract}

Keywords: Academic writing, academic reading, preservice teachers, prediction of performance, judgement of learning.

\section{Introduction}

Digital materials are frequently used in higher education (Siemens, Gašević \& Dawson, 2015), despite evidence indicating inferior comprehension of digital text relative to printed text - 'digital text inferiority' (e.g., Ben-Yehudah \& Eshet-Alkalai, 2018; Delgado, Vargas, Ackerman, \& Salmerón, 2018; Kong, Seo, \& Zhai, 2018; Singer \& Alexander, 2017a). The negative effects of reading on screen extend also to metacognitive evaluation of learning, namely, students are more overconfident in their success for reading on screen than on paper (Ackerman \& Goldschmidt, 2011; Singer \& Alexander, 2017b). One explanation for these effects is that shallow processing occurs more on screen than on paper (Chen, Cheng, Chang, et al., 2014; Wolf \& Barzillai, 2009), which leads to overconfidence and inferiority of digital text comprehension. This media effect can be reduced by "forcing" more in-depth processing on screen (Ackerman \& Lauterman, 2012). Complementing these findings are studies on reading preferences in higher-education students, which show that most students prefer to read long texts such as textbooks and academic papers in print rather than in digital format (Mizrachi, 2015). Today, 21st century skills include reading a large amount of scientific papers in digital format and writing with word processors, thus, it is necessary to develop these skills in future teachers.

The current study examined an instructional intervention for preservice teachers, which focused on developing academic reading and writing skills in digital environments. We investigated the effects of the media on academic performance (comprehension of academic papers and the quality of writing an 
integrative essay) and their corresponding confidence ratings before (prediction of performance, POP) and after (judgment of learning, JOL) each assessment. During the intervention participants received content instruction (understanding text and academic writing) together with ICT instruction over an entire semester (13 weeks, 52 hours). Here we report results for the mid-term assessment.

Our research questions (RQ) were: 1. Does an instructional intervention diminish the "digital text inferiority" effect on the academic reading and writing of preservice teachers? 2. To what extent are confidence ratings influenced by the media (paper, digital) of reading and writing?

\section{Methods}

Participants were 126 preservice teachers who were required to take a prerequisite course to improve their academic skills. Instruction took place in a computer lab using frontal-teaching methods. During the instruction phase, the instructor demonstrated reading and writing strategies for processing digitally displayed academic papers. These included extracting main ideas and organizing them with a digital graphic organizer, and integrating the ideas into a digital summary. Next, students practiced these strategies while using a common word processing software. During the assessment phase, classes were quasi-randomly assigned to a medium condition: screen $(n=71)$ or paper $(n=55)$. The mid-term assessment was similar to previous practice sessions, in which the participants were required to integrate a text they had not seen previously (i.e., unseen) with texts that they had studied and then write an integrative essay. All the texts were available to them during the assessment.

We calculated two performance indices for the mid-term assessment, based on participants answer to an open-ended question. The indices were: 1. comprehension of academic texts (i.e., identifying main ideas, connecting prior knowledge to new knowledge); and 2. academic writing quality (i.e., writing coherence and connectivity). In addition, confidence ratings were collected for each academic subskill (academic reading and academic writing) just before (POP) and right after (JOL) the mid-term assessment. The four confidence indices were: 1) POP-reading ("...do you think you will be able to understand the article?"); 2) JOL-reading ("...do you think you were able to understand the article?"); 3) POP-writing ("...do you think you will be able to write an integrative answer?"); 4) JOL-writing ("...do you think you were able to write the integrative answer?"). We also calculated calibration measures for each type of confidence rating (i.e., POP-calibration and JOL-calibration). Calibration is the difference between the actual performance and the metacognitive judgement of performance.

\section{Results}

\subsection{Media effects on performance (RQ1)}

Two performance indices were derived from the mid-term assessment: academic text comprehension and writing quality (see methods). There were no significant effects of the media (digital, paper) on academic reading: digital $(59.17 \%)$ and paper $(57.56 \%), t(121)=-0.42, p=.67, d=0.08$; nor on academic writing: digital $(66.4 \%)$ and paper $(70.4 \%), t(121)=0.82, p=.41, d=0.15)$. These results show that emphasizing in-depth processing through a cycle of instruction and practice sessions did indeed reduce the digital text inferiority effect.

\subsection{Metacognitive judgements (RQ2)}

Confidence ratings for each academic subskill (text comprehension and writing quality) were collected before (POP) and after (JOL) the mid-term assessment. Before participants began the assessment, their confidence ratings (POP) were significantly higher for the digital relative to print condition, for both academic reading and writing. As reflected by the significant media effect observed in both POP measures. For POP-reading, digital $(68.68 \%)$ was larger than paper $(58.13 \%), t(117)=-2.65$, $p<.01, d=0.49$. For POP-writing, digital $(71.75 \%)$ was larger than paper $(58.53 \%), t(121)=-3.73$, $p=.001, d=0.69$. Despite this overconfidence, analyses of POP-calibration indicated that the paper group $(19.55 \%$ bias $)$ was significantly more calibrated than the digital group $(26.55 \%$ bias $)$ in their evaluation of reading comprehension, $t(117)=-2.19, p=.03 ; d=0.44$. The groups did not differ in their POP-calibration for writing quality. In contrast, after the assessment, calibration analyses for JOL showed that the digital group $(23.33 \%$ bias) was significantly better at evaluating their writing quality than the paper group $(33.25 \%$ bias $), t(117)=2.72, p=.026 ; d=0.49$. 


\section{Discussion}

Our findings show that the instructional intervention was effective in reducing the media effect on academic performance, as the mid-term assessment showed no significant effect of the media (digital, paper) on academic reading or writing. This bares important educational implications, namely, to encourage preservice teachers to develop in-depth processing of digital text, which should help minimize the inferiority of digital text comprehension (Delgado et al., 2018; Kong et al., 2018; Singer \& Alexander, 2017a).

Consistent with the literature, higher levels of confidence in academic reading were observed in the digital as compared to paper setting (Ackerman \& Goldschmidt, 2011). A similar pattern of findings was observed for academic writing ability. To the best of our knowledge, confidence ratings have not been assessed for digital versus paper based writing. Thus, our finding in this area is novel and worth further investigation. Interestingly, after the mid-term assessment, the digital group's evaluation of academic writing (JOL-writing) was in fact less biased than the paper group's evaluation of their writing performance. In contrast, evaluation of reading comprehension (POP-reading) was more calibrated in the paper group than the digital group.

These encouraging findings suggest the importance of developing academic subskills (academic reading and writing) in digital environments, particularly in preservice teachers that are entrusted with educating our youth on 21 st century skills. Given the prevalence of digital academic materials in higher education, it is important to increase students' awareness of the effect the media has one's own evaluation of reading and writing performance.

\section{References}

Ackerman, R., \& Goldsmith, M. (2011). Metacognitive Regulation of Text Learning: On Screen Versus on Paper. Journal of Experimental Psychology: Applied, 17(1), 18-32.

Ackerman, R., \& Lauterman, T. (2012). Taking reading comprehension exams on screen or on paper? A metacognitive analysis of learning texts under time pressure. Computers in Human Behavior, 28(5), 1816-1828.

Ben-Yehudah, G., \& Eshet-Alkalai, Y. (2018). The contribution of text-highlighting to comprehension: A comparison of print and digital reading. Journal of Educational Multimedia and Hypermedia, 27(2), 153-178.

Chen, G., Cheng, W., Chang, T., Zheng, X., \& Huang, R. (2014). A comparison of reading comprehension across paper, computer screens, and tablets: Does tablet familiarity matter? Journal of Computers in Education, 1, 213-225.

Delgado, P., Vargas, C., Ackerman, R., \& Salmerón, L. (2018). Don't throw away your printed books: A meta-analysis on the effects of reading media on reading comprehension. Educational Research Review.

Kong, Y., Seo, Y. S., \& Zhai, L. (2018). Comparison of reading performance on screen and on paper: A meta-analysis. Computers \& Education, 123, 138-149.

Mizrachi, D. (2015). Undergraduates' academic reading format preferences and behaviors. The Journal of Academic Librarianship, 41, 301-311.

Siemens, G., Gašević, D., \& Dawson, S. (2015). Preparing for the digital university: A review of the history and current state of distance, blended, and online learning. http://linkresearchlab.org/PreparingDigitalUniversity.pdf

Singer, L. M., \& Alexander, P. A. (2017a). Reading on paper and digitally: What the past decades of empirical research reveal. Review of Educational Research, 87(6), 1007-1041.

Singer, L. M., \& Alexander, P. A. (2017b). Reading Across Mediums: Effects of Reading Digital and Print Texts on Comprehension and Calibration. Journal of Experimental Education, 85(1), $155-172$.

Wolf, M., Barzillai, M., (2009). The importance of deep reading. Educational Leadership, 66(6), 32-37. 